[19] Quinn, J.-A., Munoz, F. M., Gonik, B., Frau, L. (2016). Preterm birth: Case definition \& guidelines for data collection, analysis, and presentation of immunisation safety data. Vaccine, 34 (49), 6047-6056. doi: http://doi.org/10.1016/j.vaccine.2016.03.045

[20] Dakhale, G. N., Hiware, S. K., Shinde, A. T. (2012). Basic biostatistics for post-graduate students. Indian Journal of Pharmacology, 44 (4), 435-442. doi: http://doi.org/10.4103/0253-7613.99297

[21] Oxlund, B. S., Ortoft, G., Brüel, A., Danielsen, C. C., Oxlund, H., Uldbjerg, N. (2010). Cervical collagen and biomechanical strength in non-pregnant women with a history of cervical insufficiency. Reproductive Biology and Endocrinology, 8, 92. doi: http://doi.org/10.1186/1477-7827-8-92

[22] Bohiltea, R. E., Munteanu, O., Turcan, N., Baros, A., Bodean, O., Voicu, D., Cirstoiu, M. M. (2016). A debate about ultrasound and anatomic aspects of the cervix in spontaneous preterm birth. Journal of Medicine and Life, 9 (4), 342-347.

\title{
PROGNOSTIC VALUE OF COGNITIVE TESTS AND THEIR COMBINATION IN PATIENTS WITH CHRONIC HEART FAILURE AND REDUCED LEFT VENTRICULAR EJECTION FRACTION
}

\author{
Leonid Voronkov \\ Department of heart failure \\ National Scientific Center "M. D. Strazhesko Institute of Cardiology" \\ 5 Narodnoho opolchennya str., Kyiv, Ukraine, 02000 \\ lgvoronkov@gmail.com \\ Anastasiia Solonovych \\ Department of heart failure \\ National Scientific Center "M. D. Strazhesko Institute of Cardiology" \\ 5 Narodnoho opolchennya str., Kyiv, Ukraine, 02000 \\ stasyasol85@gmail.com \\ Alina Liashenko \\ Department of heart failure \\ National Scientific Center "M. D. Strazhesko Institute of Cardiology" \\ 5 Narodnoho opolchennya str., Kyiv, Ukraine, 02000 \\ lyashenko2007@ukr.net \\ Ivanna Revenko \\ National Scientific Center "M. D. Strazhesko Institute of Cardiology” \\ 5 Narodnoho opolchennya str., Kyiv, Ukraine, 02000 \\ ivarev@ukr.net
}

\footnotetext{
Abstract

Impaired cognitive function (CF) is common among patients with $\mathrm{CHF}$ and is an additional factor impairing the quality of life, adherence to treatment, and hence the clinical prognosis in this category of patients.

The aim of this work was to study the prognostic significance of individual cognitive tests, as well as their combination in patients with CHF with a reduced left ventricular ejection fraction (LV EF).

Materials and methods. The study was conducted in the Department of Heart Failure of National Scientific Center "M.D. Strazhesko Institute of Cardiology" National Academy of Medical Sciences of Ukraine, in the period from 01/01/2016 to 04/27/2018. A total of 124 patients with CHF between the ages of 18 and 75 years, II-IV functional classes by NYHA were examined. The cognitive function was assessed using the Schulte test, Mini-Mental State Examination scale (MMSE); HADS scale. Cognitive dysfunction (CD) was considered as MMSE $\leq 26$ points. To construct the survival curves and the onset of the combined critical event
} 
(death or hospitalization), the Kaplan - Meier method was used, the significance of the differences between the curves was determined using the log-rank criterion. Differences were considered statistically significant at $\mathrm{p}<0.05$.

Results. The MMSE scale was highly informative regarding the prediction of survival and the onset of a combined critical event (death or hospitalization) in patients with CHF and reduced LVEF even after correction of the compared groups by age and functional class according to NYHA ( $\mathrm{p}=0.025$ and $\mathrm{p}=0.049$, respectively). Using the same sample, Schulte showed low prognostic significance regarding survival and reliable informativeness regarding the onset of the combined critical event, which, however, was leveled after correcting the compared samples by age and functional class NYHA ( $p=0.798$ and $p=0.240$, respectively). The inclusion in the prognostic algorithm of estimating the sum of points on the HADS depression scale allowed increasing the degree of reliability of differences between the compared groups of patients with $\mathrm{CD}$ and without $\mathrm{CD}$ in terms of both long-term survival and the onset of a combined critical event (death or hospitalization) ( $\mathrm{p}=0.006$ and $\mathrm{p}=0.001$ respectively).

Conclusions. The MMSE scale is informative regarding the prediction of survival and the onset of a combined critical event in patients with CHF and reduced LVEF. Schulte's test does not have the prognostic information indicated above, however, the inclusion in the algorithm of the sum of points on the HADS depression scale allows to increase the degree of statistical confidence in the compared groups.

Keywords: heart failure, cognitive dysfunction, depression, neuropsychological testing, survival prediction.

\section{Introduction}

To date, chronic heart failure (CHF) is one of the most important problems of modern cardiology, which is largely due to its poor clinical prognosis. The mortality rate from CHF in the first five years after diagnosis has reached $59 \%$ among men and $45 \%$ among women. One out of 4-5 patients dies within the first year after the diagnosis of CHF is diagnosed [1]. In this context, the importance of determining the role of various factors that can influence the course and prognosis of this disease is of great importance in CHF.

Impaired cognitive function $(\mathrm{CF})$ is common among patients with $\mathrm{CHF}$ [2] and is an additional factor impairing the quality of life, adherence to treatment, and, consequently, the clinical prognosis in this category of patients [3]. It is known that the presence of cognitive dysfunction (CD) increases hospital and non-hospital mortality of patients with CHF, so in the study of Zuccala and co-authors the hospital mortality rate of patients with HF was almost 5 times higher in the presence of CD [4].

For the assessment of $\mathrm{CF}$, various screening neuropsychological tests are used, which make it possible to assess the status of CF, without the obligatory involvement of a narrow specialist. The most widely used of them in clinical practice today are the brief scale for assessing mental status MMSE (MiniMentalStateExamination) [5] and the Schulte's test [6].

Therefore, if the prognostic value of the fact of the presence of a CD has been established, then the corresponding prognostic information content of the results of individual cognitive tests has not been previously studied. This approach seems relevant from the standpoint of optimizing individual prediction of clinical outcomes of CHF.

\section{Aim of the research}

Study of the significance of individual cognitive tests, as well as their combination in patients with CHF with a reduced left ventricular ejection fraction (LVEF) for predicting long-term survival and the onset of a combined critical event (death or hospitalization).

\section{Materials and methods}

The study was conducted in the department of heart failure of National Scientific Center "M. D. Strazhesko Institute of Cardiology" National Academy of Medical Sciences of Ukraine, in the period from $01 / 01 / 2016$ to $04 / 27 / 2018$. The length of observation period was 27.5 months. The beginning of the observation was considered the date of primary hospitalization, the end point - the date of the patient's death or survival by April 27, 2018. The survival of the subjects was assessed using a telephone survey or postal correspondence. 
We examined 124 patients with stable CHF and reduced LV EF $(<40 \%)(\mathrm{Me}=28.0(21 ; 35))$ aged 25 to 75 years $(\mathrm{Me}=63.0(54 ; 68.3))$ those who were hospitalized in the department of heart failure of the State Institution National Research Center "Institute of Cardiology named after acad. N. D. Strazhesko". Among the studied men dominated - $83 \%$ (103 people). Etiological factor in the development of CHF was coronary heart disease (CHD) (94 people) or dilated cardiomyopathy (DCM) (19 people). A history of concomitant arterial hypertension (AH) was 92 people, diabetes mellitus (DM) - 35 people. About half of the patients had a permanent or persistent form of atrial fibrillation (AF) (Table 1).

The study did not include patients older than 75 years, with an acute violation of cerebral circulation in history, with organic brain lesions (traumatic brain injury, infectious diseases, tumors, etc.), with neurodegenerative diseases (Alzheimer's disease, Parkinson's and others) with cancer and infectious diseases, with hypertrophic cardiomyopathy, inflammatory and restrictive myocardial lesions, with acute coronary syndrome, myocardial infarction (MI) older than 3 months, with retained organic and congenital heart defects, as well as those who took drugs that can affect the CF (except for drugs that are part of the standard treatment protocol for heart failure).

The diagnosis of the underlying disease was determined on the basis of general clinical examination, instrumental and laboratory methods. CHF was diagnosed according to the recommendations for the diagnosis and treatment of heart failure of the European Society of Cardiology and the relevant recommendations of the Association of Cardiologists of Ukraine [7-9]. Patients were included in the study in the phase of clinical compensation while receiving optimized standard pharmacotherapy (ACE inhibitors, sartans, beta-blockers, mineralcorticoid receptor antagonists, diuretics). The observation period was 27.5 months.

The compulsory examination protocol included electrocardiography, standard echocardiography, routine laboratory tests for determining glomerular filtration rate (GFR) using the EPI formula [10], quality of life assessment using the Minnesota Living with Heart Failure Questionnaire (MLHFQ) questionnaire activity - DukeActivityStatusIndex (DASI) using the Duke University questionnaire [11, 12]. To assess the state of CF, standardized methods of neuropsychological testing were used - the abbreviated scale of the mental status study Mini-Mental State Examination (MMSE), Schulte's test [5, 13]; using the HADS scale, levels of depression and anxiety were assessed $[14,15]$.

Statistical processing of information was carried out using Microsoft Exel, IBMSPSSStatistics (version 22.0). The normal distribution was estimated using the Kolmogorov-Smirnov test. Since the distribution of intragroup quantitative indicators, as a rule, differed from the normal, the median and interquartile range (Me (LQ; UQ)) were used for the description. The absolute and relative frequencies ( $\mathrm{n}, \%$ ) were calculated to describe the qualitative features. The hypothesis about the reliability of the difference in the values of quantitative indicators in the compared groups was checked using the non-parametric Mann-Whitney test, for qualitative ones using the $\chi^{2}$-Pearson criterion with the construction of contingency tables. To construct the survival curves and the onset of a combined critical event (death or hospitalization), the Kaplan-Meier method [16] was used, the significance of the differences between the curves was determined using the log-rank criterion [17]. Differences were considered statistically significant at $\mathrm{p}<0.05$.

\section{Results}

The criterion for the presence of the CD was the number of points on the scale of MMSE $\leq 26$. It is noteworthy that the median score on the MMSE scale also amounted to 26 .

Among the studied CDs according to the MMSE test, there was in most cases, that is, in $85(68.6 \%)$ patients examined. The studied groups were comparable in terms of gender, prevalence of persistent/persistent forms of AF, and concomitant pathology - anemia, chronic obstructive pulmonary disease (COPD), and diabetes mellitus (DM) (Table 1).

At the same time, patients with more severe functional class according to NYHA (III-IV) prevailed among those studied with CD (Table 1). 
Table 1

Comparability of patient groups with and without $\mathrm{CD}$ in terms of gender composition, distribution by functional classes and comorbidities

\begin{tabular}{|c|c|c|c|c|c|}
\hline \multirow{2}{*}{ Indicators } & \multicolumn{2}{|c|}{ Patients with $\mathrm{CD}(\mathrm{n}=\mathbf{8 5})$} & \multicolumn{2}{|c|}{ Patients without $C D(n=39)$} & \multirow{2}{*}{$\mathbf{P}$} \\
\hline & $\mathbf{n}$ & $\%$ & $\mathbf{n}$ & $\%$ & \\
\hline Men, $(n=103)$ & 68 & 80 & 35 & 89.7 & 0.210 \\
\hline NYHA II FC (n=44) & 22 & 25.9 & 22 & 56.4 & 0.001 \\
\hline NYHA III-IV FC (n=80) & 63 & 74.1 & 17 & 43.6 & 0.001 \\
\hline $\operatorname{AF}(n=68)$ & 51 & 60 & 17 & 43.6 & 0.066 \\
\hline $\mathrm{DM}(\mathrm{n}=35)$ & 28 & 32.9 & 7 & 17.9 & 0.055 \\
\hline $\operatorname{COPD}(n=21)$ & 14 & 16.5 & 7 & 17.9 & 0.513 \\
\hline Anemia $(n=36)$ & 27 & 31.8 & 9 & 23.1 & 0.220 \\
\hline
\end{tabular}

Note: AF-atrial fibrillation; DM - diabetes mellitus; COPD - chronic obstructive pulmonary disease

According to hemodynamic parameters - the value of systolic (SBP) and diastolic (DBP) blood pressure, heart rate (HR) and the LV EF value, the studied groups were comparable. However, among patients with $\mathrm{CD}$, the older age group prevailed (Table 2).

Table 2

Comparability of patient groups with and without $\mathrm{CD}$ in terms of age and hemodynamic parameters

\begin{tabular}{|c|c|c|c|}
\hline Indicators & $\begin{array}{c}\text { CD (MMSE } \leq 26 \text { points) }(n=85) \\
\text { Me (LQ; HQ) }\end{array}$ & $\begin{array}{c}\text { Without CD }(\text { MMSE }>26 \text { points) }(n=39) \\
\text { Me (LQ; HQ) }\end{array}$ & $\mathbf{P}$ \\
\hline Age, years & $64(57 ; 69,5)$ & $55(44 ; 64)$ & 0.002 \\
\hline $\mathrm{HR}, \mathrm{bpm}$ & $75(68 ; 85)$ & $74(68 ; 82)$ & 0.461 \\
\hline SBP, mm Hg & $110(105 ; 120)$ & $110(100 ; 120)$ & 0.476 \\
\hline DBP, mm Hg & $80(70 ; 85)$ & $70(70 ; 80)$ & 0.264 \\
\hline LV EF, \% & $29(22 ; 35)$ & $27(21 ; 35)$ & 0.637 \\
\hline
\end{tabular}

Note: $H R$ - heart rate; SBP - systolic blood pressure; DBP - diastolic blood pressure; $L V E F$ - left ventricular ejection fraction

During the first stage of work, we studied the long-term clinical prognosis of patients with CHF, depending on the presence of CD.

As seen in Fig. 1, the group of patients with CD had a significantly worse clinical prognosis in relation to the onset of death, compared with patients without CD.

In Fig. 2 shows that patients with $\mathrm{CD}$ had a significantly worse clinical prognosis regarding the onset of a combined critical event (death or hospitalization).

The next stage of work was the comparison of the survival curves and the onset of the combined critical event for groups of patients with $\mathrm{CD}$ and without $\mathrm{CD}$ after leveling them up by age and functional class according to NYHA, which, as is known, are themselves markers of an unfavorable clinical prognosis of patients with CHF [18].

After correction of the compared groups of patients by age and NYHA functional class, significant differences in survival and the onset of the combined critical event persisted, which indicates the effect on the worst prognosis of the CD (Fig. 3, 4). 




Fig. 1. Survival curves of patients with CHF and reduced LV EF depending on the presence of CD, $\mathrm{p}=0.043$; censored with and without a CD - the subjects who did not die at the time of the end of the observation period; $C D$ - cognitive dysfunction; without $C D$ - without cognitive dysfunction

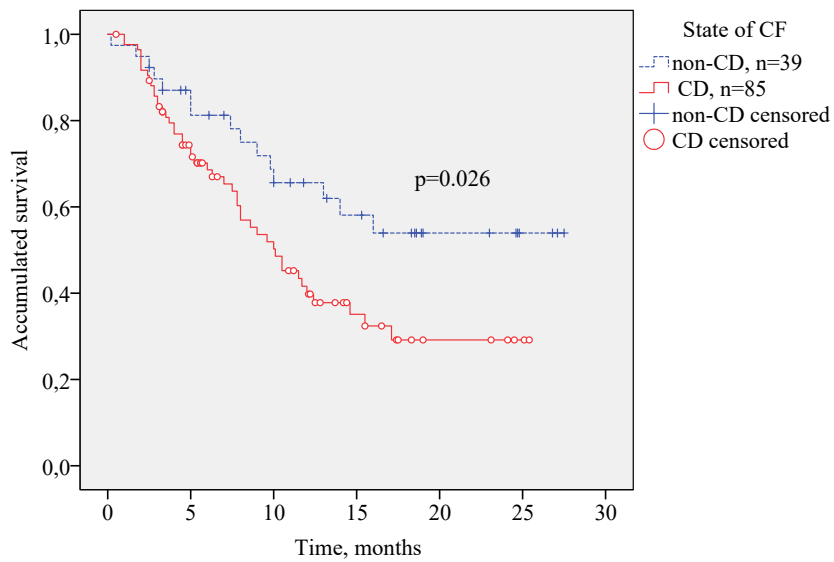

Fig. 2. Curves of the onset of the combined critical event (death or hospitalization) depending on the presence of the $\mathrm{CD}, \mathrm{p}=0.026$ : censored with $\mathrm{CD}$ and without $\mathrm{CD}$ are the subjects that did not have the combined critical event at the end of the observation period

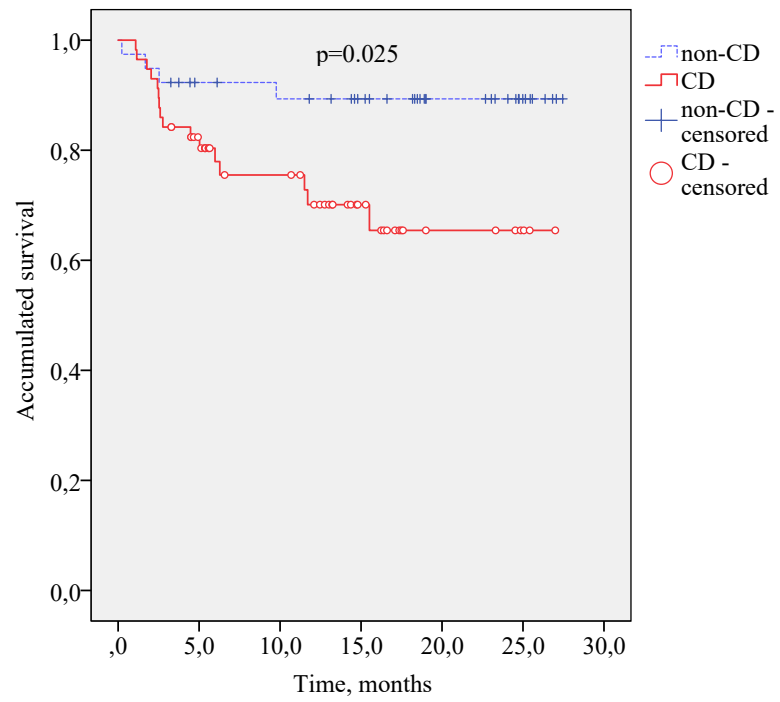

Fig. 3. Survival curves of patients with CHF and reduced LV EF depending on the presence of $\mathrm{CD}$, after correction of the compared groups by age and FC by the NYHA 


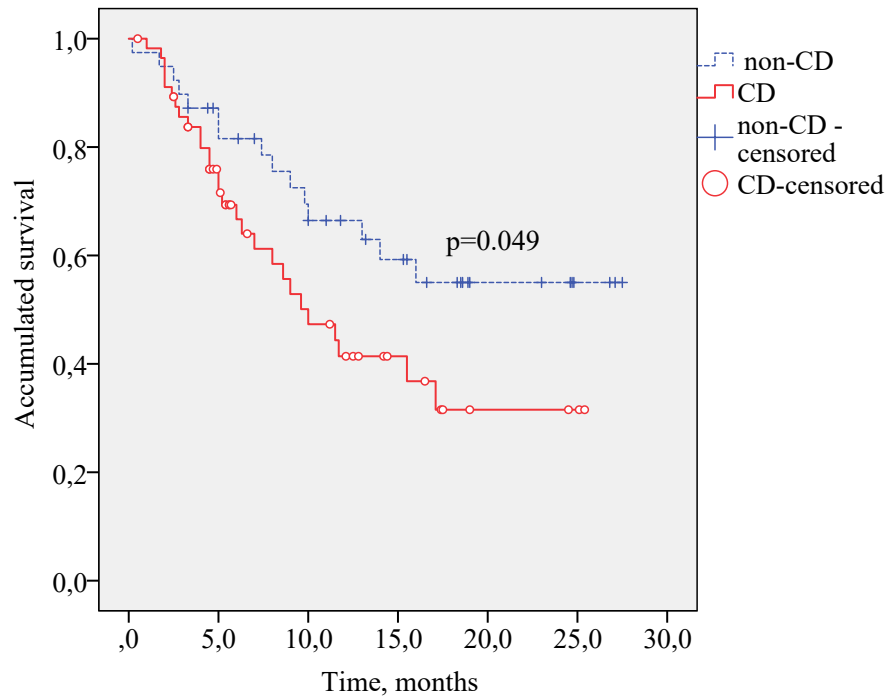

Fig. 4. Curves of the onset of the combined critical event (death or hospitalization), depending on the presence of $\mathrm{CD}$, after correction of the compared groups by age and FC by the NYHA

At the next stage of our work, we tried to determine the effect of the time taken for the Schulte's test to perform on the clinical prognosis of patients with CHF. To this end, we divided the subjects into 2 groups according to the median $(54,15)$ execution time of the Schulte's sample: $\leq 54.15$ seconds. $(n=62)$ and $>54.15$ sec. $(n=62)$. It should be noted that in individuals with $C D$, the median of the Schulte's sample execution time was 61 seconds (min-32 s; max-110 s).

As seen in Fig. 5, 6, the time taken to Schulte's test did not significantly affect the mortality rate of patients with CHF, while the incidence of the combined critical event was significantly higher in the group of patients with the worst performance of the Schulte's test. However, this difference was leveled after grading of the studied groups according to age and NYHA class (Fig. 7, 8).

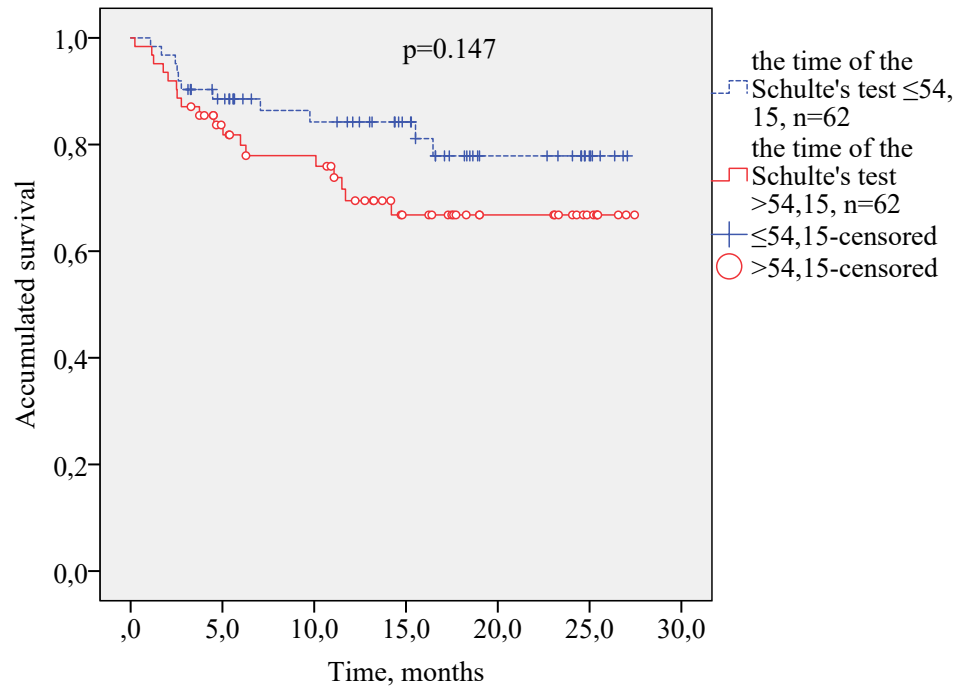

Fig. 5. Survival curves for patients with $\mathrm{CHF}$ and reduced LV EF depending on the median of the time taken for the Schulte's test.

At the same time, when dividing patients into two groups according to a combination of two signs, such as "the time for performing the Schulte's test $>$ medians (54.15)" + "the sum of points for the HADS depression $>$ medians (6)" ( $n=39$ vs $n=85)$ allowed to increase the degree of statistical reliability of differences between the indicated survival rates and the onset of the combined critical 
event (Fig. 9, 10). It should be noted that in individuals with $C D$, the median amount of points in the base of the HADS depression was 7 ( $\min =0$; $\max =16$ points).



Fig. 6. Curves of the onset of the combined critical event (death or hospitalization) depending on the median of the time of the execution of the Schulte's sample

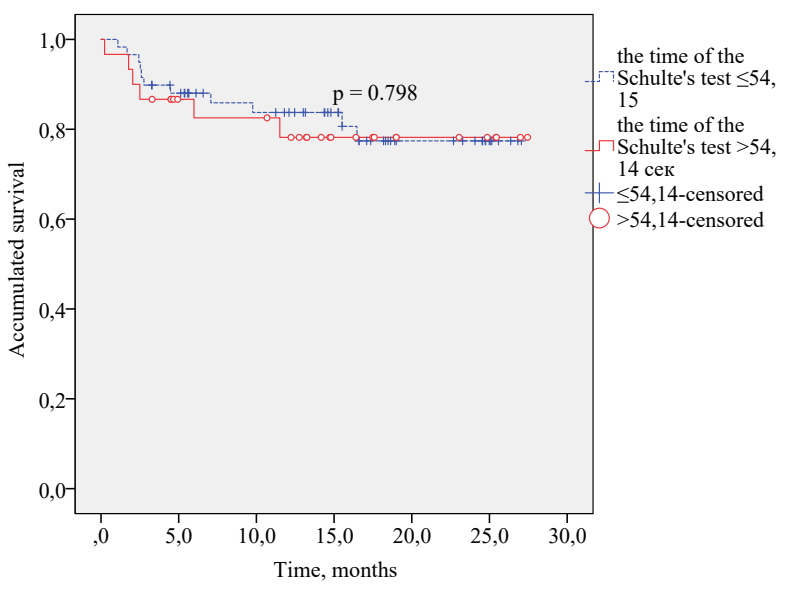

Fig. 7. Survival curves for patients with CHF and reduced LV EF for the patient, depending on the median of the time taken to complete the Schulte's test after correcting the groups for age and FC by the NYHA

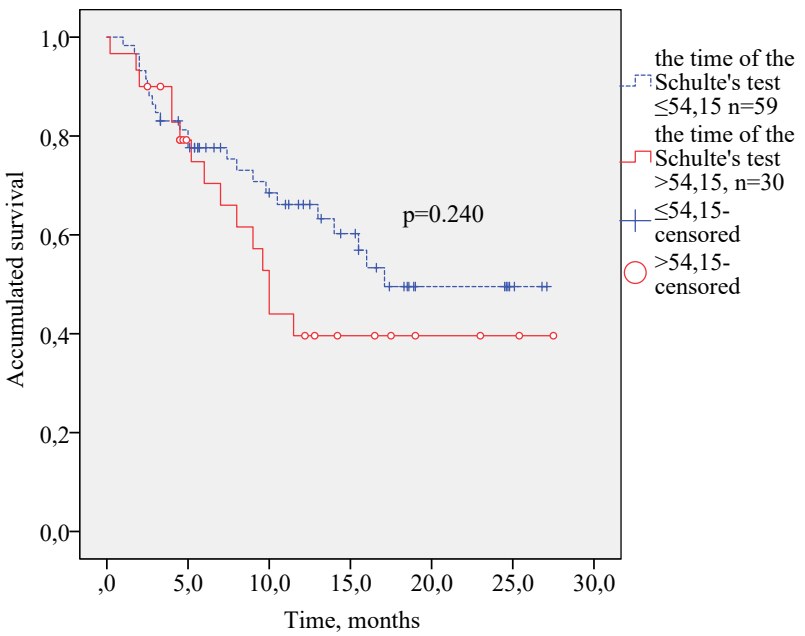

Fig. 8. Curves of the onset of the combined critical event (death or hospitalization) depending on the median of the time of the Schulte's sample after correction of the groups by age and FC by the NYHA 


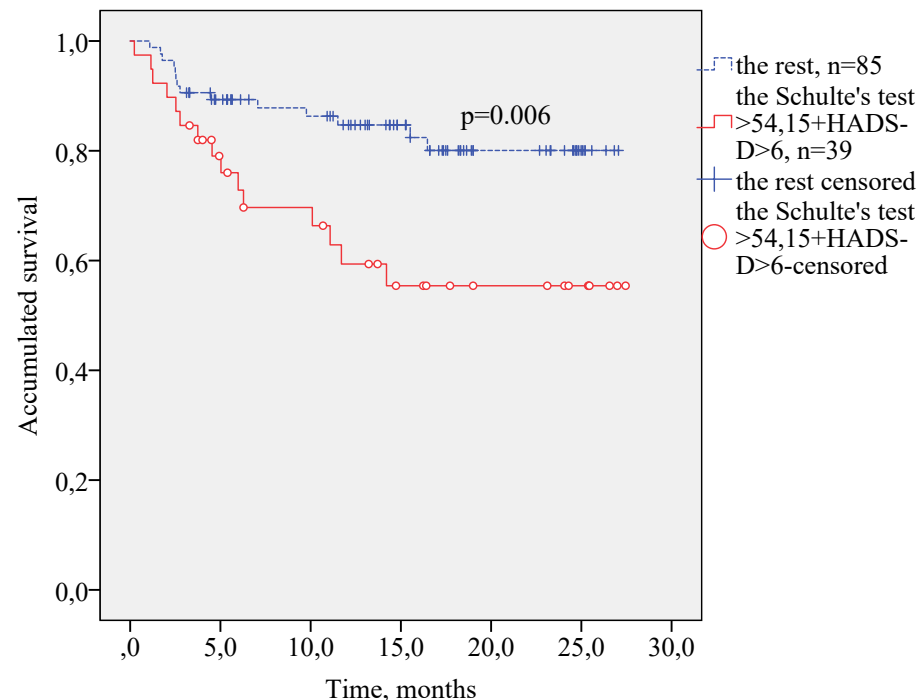

Fig. 9. Survival curves of patients with CHF and reduced LV EF when divided into groups by a combination of 2 signs - "time to perform a Schulte's test $>$ medians" + "sum of points on the base of the HADS depression> medians"

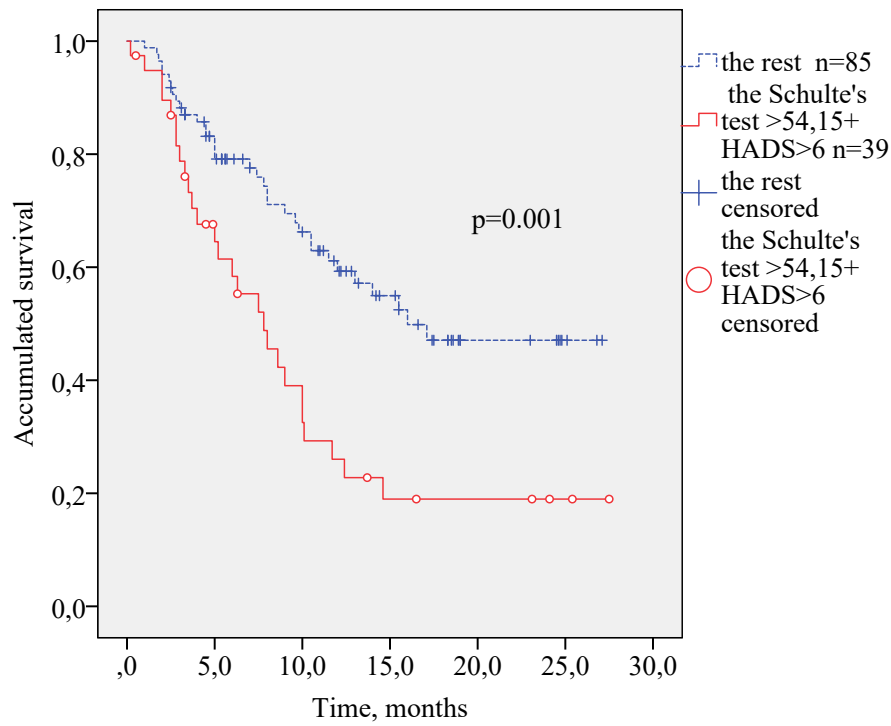

Fig. 10. Curves of the onset of the combined critical event (death or hospitalization) of patients with chronic heart failure and reduced LV EF when divided into groups by a combination of 2 signs - "time to perform a Schulte's test> medians" + "sum of points on the base of the HADS depression> medians"

\section{Discussion}

The study allowed us to confirm previously obtained data that the presence of CD is associated with poorer survival and higher hospitalization rates for patients with CHF and reduced LV $\mathrm{EF}$ [3]. At the same time, our analysis of the prognostic significance of individual indicators of CF, along with confirmation of the prognostic validity of the total score on the MMSE scale, made it possible to state that there is no reliable relationship between the time when the Schulte's sample was run and the long-term prognosis of our patients.

Along with this, we obtained data that the inclusion in the prognostic algorithm for estimating the sum of points by the base of the HADS depression allowed increasing the degree of reliability of differences between the respective groups. In this regard, it is appropriate to mention the 
data on the close relationship of CD and depressive manifestations in patients with CHF [20]. It has been established that the role of depression in the formation of CD is very significant and consists, including in reducing motivational incentives for the assimilation and processing of information [21]. Depression negatively affects not only the prognosis of CHF, but also its clinical course [22]. A number of authors demonstrated the effect of depression on mortality, functional status and quality of life of patients with CHF in proportion to the severity of depressive symptoms [23, 24]. In patients with severe depression, the risk of death within 6 years is 2.5 times higher than in patients without depression [25]. J. Jünger et al. found that depression is a risk factor for death, regardless of the functional class of CHF, LV EF, and peak oxygen consumption [26].

The obtained data can serve as a basis for the next stage of work, consisting in clarifying the possibilities of a comprehensive assessment of the psychological and emotional status in its part concerning the state of CF and the presence / severity of depressive manifestations, with the aim of individually predicting the outcomes of this syndrome.

\section{Conclusions}

1. The MMSE scale is highly informative regarding the prediction of long-term survival and the onset of a combined critical event (mortality or hospitalization) in patients with CHF and reduced LV EF even after correction of the compared groups by age and NYHA functional class.

2. The use of Schulte's test showed a low prognostic value regarding survival; its use demonstrated sufficient informativeness regarding the onset of the combined critical event, which, however, was leveled after correction of the compared samples by age and NYHA functional class.

3. The inclusion in the prognostic algorithm of estimating the sum of points of the HADS depression scale allows to increase the degree of reliability of differences between the compared groups of patients with $\mathrm{CD}$ and non-CD both in terms of long-term survival and the onset of a combined critical event (mortality or hospitalization).

\section{References}

[1] Younus, A., Aneni, E. C., Spatz, E. S., Osondu, C. U., Roberson, L., Ogunmoroti, O. et. al. (2016). A Systematic Review of the Prevalence and Outcomes of Ideal Cardiovascular Health in US and NonUS Populations. Mayo Clinic Proceedings, 91 (5), 649-670. doi: http://doi.org/10.1016/j.mayocp.2016.01.019

[2] Cohen, M. B., Mather, P. J. (2007). A Review of the Association Between Congestive Heart Failure and Cognitive Impairment. The American Journal of Geriatric Cardiology, 16 (3), 171-174. doi: http:// doi.org/10.1111/j.1076-7460.2007.06563.x

[3] Celutkiene, J., Vaitkevicius, A., Jakstiene, S., Jatuzis, D. (2016). Cognitive Decline in Heart Failure: More Attention is Needed. Cardiac Failure Review, 2 (2), 106-109. doi: http://doi.org/10.15420/ cfr.2016:19:2

[4] Zuccalà, G., Pedone, C., Cesari, M., Onder, G., Pahor, M., Marzetti, E. et. al. (2003). The effects of cognitive impairment on mortality among hospitalized patients with heart failure. The American Journal of Medicine, 115 (2), 97-103. doi: http://doi.org/10.1016/s0002-9343(03)00264-x

[5] Zaharov, V. V. (2011). Neiropsihologicheskie testy. Neobhodimost' i vozmozhnost' primeneniia. CONSILIUM MEDICUM, 13 (2), 82-90.

[6] Adams, K. M., Grant, I. (2009). Neuropsychological Assessment of Neuropsychiatric and Neuromedical Disorders. New York: Oxford University Press.

[7] Voronkov, L. G., Amosova, K. M., Bagrii, A. E., Dziak, G. V. (Eds.) (2012). Rekomendacii z diagnostiki ta likuvannia hronichnoi sercevoi nedostatnosti. Kyiv: MORION, 52.

[8] Ponikowski, P., Voors, A. A., Anker, S. D., Bueno, H., Cleland, J. G. F. et. al. (2016). 2016 ESC Guidelines for the diagnosis and treatment of acute and chronic heart failure. European Journal of Heart Failure, 18 (8), 891-975. doi: http://doi.org/10.1002/ejhf.592

[9] Inker, L., Perrone, R. D.; Sterns, R. H. (Ed.) Assessment of kidney function. UpToDate. Waltham. Available at: https://www.uptodate.com/contents/assessment-of-kidney-function Last accessed: 09.05.2014

[10] Voronkov, L. G., Parashheniuk, L. P. (2010). Kachestvo zhizni pri serdechnoi nedostatochnosti: aktual'nye aspekty. Serceva nedostatnist', 2, 12-16. 
[11] Iqbal, J., Francis, L., Reid, J., Murray, S., Denvir, M. (2010). Quality of life in patients with chronic heart failure and their carers: a 3-year follow-up study assessing hospitalization and mortality. European Journal of Heart Failure, 12 (9), 1002-1008. doi: http://doi.org/10.1093/eurjhf/hfq114

[12] Coutinho-Myrrha, M. A., Dias, R. C., Fernandes, A. A. (2014). Duke Activity Status Index for Cardiovascular Diseases: validation of the Portuguese Translation. Arquivos Brasileiros de Cardiologia, 102 (4), 383-390.

[13] Zakharov, V. V. (2011). Neuropsychological tests. Necessity and possibility of application. CONSILIUM MEDICUM, 13 (2), 82-90.

[14] Zigmond, A. S., Snaith, R. P. (1983). The Hospital Anxiety and Depression Scale. Acta Psychiatrica Scandinavica, 67 (6), 361-370. doi: http://doi.org/10.1111/j.1600-0447.1983.tb09716.x

[15] Ceccarini, M., Manzoni, G. M., Castelnuovo, G. (2014). Assessing Depression in Cardiac Patients: What Measures Should Be Considered? Depression Research and Treatment, 2014, 1-17. doi: http:// doi.org/10.1155/2014/148256

[16] Kishore, J., Goel, M., Khanna, P. (2010). Understanding survival analysis: Kaplan-Meier estimate. International Journal of Ayurveda Research, 1 (4), 274-278. doi: http://doi.org/10.4103/0974-7788.76794

[17] Schmidt, R., Faldum, A., Kwiecien, R. (2017). Adaptive designs for the one-sample log-rank test. Biometrics, 74 (2), 529-537. doi: http://doi.org/10.1111/biom.12776

[18] Díez-Villanueva, P., Alfonso, F. (2016). Heart failure in the elderly. Journal of Geriatric Cardiology, 13 (2), 115-117.

[19] Aaronson, K. D., Cowger, J. (2012). Heart Failure Prognostic Models. Circulation: Heart Failure, 5 (1), 6-9. doi: http://doi.org/10.1161/circheartfailure.111.965848

[20] Sauvé, M. J., Lewis, W. R., Blankenbiller, M., Rickabaugh, B., Pressler, S. J. (2009). Cognitive Impairments in Chronic Heart Failure: A Case Controlled Study. Journal of Cardiac Failure, 15 (1), 1-10. doi: http://doi.org/10.1016/j.cardfail.2008.08.007

[21] Mbakwem, A., Aina, F., Amadi, C. (2016). Depression in Patients with Heart Failure: Is Enough Being Done? Cardiac Failure Review, 2 (2), 110-112. doi: http://doi.org/10.15420/cfr.2016:21:1

[22] Suzuki, H., Matsumoto, Y., Ota, H., Sugimura, K., Takahashi, J., Ito, K. et. al. (2016). Hippocampal Blood Flow Abnormality Associated With Depressive Symptoms and Cognitive Impairment in Patients With Chronic Heart Failure. Circulation Journal, 80 (8), 1773-1780. doi: http://doi.org/10.1253/circj. cj-16-0367

[23] Fan, H., Yu, W., Zhang, Q., Cao, H., Li, J., Wang, J. et. al. (2014). Depression after heart failure and risk of cardiovascular and all-cause mortality: A meta-analysis. Preventive Medicine, 63, 36-42. doi: http://doi.org/10.1016/j.ypmed.2014.03.007

[24] Kop, W. J., Synowski, S. J., Gottlieb, S. S. (2011). Depression in Heart Failure: Biobehavioral Mechanisms. Heart Failure Clinics, 7 (1), 23-38. doi: http://doi.org/10.1016/j.hfc.2010.08.011

[25] Moraska, A. R., Chamberlain, A. M., Shah, N. D., Vickers, K. S., Rummans, T. A., Dunlay, S. M. et. al. (2013). Depression, Healthcare Utilization, and Death in Heart Failure. Circulation: Heart Failure, 6 (3), 387-394. doi: http://doi.org/10.1161/circheartfailure.112.000118

[26] Jünger, J., Schellberg, D., Müller-Tasch, T., Raupp, G., Zugck, C., Haunstetter, A. et. al. (2005). Depression increasingly predicts mortality in the course of congestive heart failure. European Journal of Heart Failure, 7 (2), 261-267. doi: http://doi.org/10.1016/j.ejheart.2004.05.011 